\title{
Evaluation of bioavailability of light rare earth elements to wheat (Triticum aestivum L.) under field conditions
}

\author{
Jing Fang, Bei Wen, Xiao-Quan Shan *, Huan-hua Wang, Jin-ming Lin, Shu-zhen Zhang \\ State Key Laboratory of Environmental Chemistry and Ecotoxicology, Research Center for Eco-Environmental Sciences, \\ Chinese Academy of Sciences, P.O. Box 2871, Beijing 100085, China
}

Received 26 August 2006; received in revised form 29 March 2007; accepted 12 May 2007

Available online 3 July 2007

\begin{abstract}
Current bioavailability assessments of light rare earth elements (LREEs) are often carried out under greenhouse conditions. This work was to identify which soil properties are mostly related to LREE bioavailability and what extraction method is the most promising approach for assessing bioavailability of LREEs to wheat under field conditions. A comparison was made between four commonly used extractants (DTPA, EDTA, $\mathrm{CaCl}_{2}$ and $\mathrm{CH}_{3} \mathrm{COOH}$ ), and the results suggested that the LREE concentrations in wheat roots significantly correlated with soil pH and amorphous Fe oxide contents in soils, but were independent of soil organic matter (SOM), crystalline Fe and Mn oxide contents, and cation exchange capacity (CEC). The contents of LREEs in shoots were independent of any soil properties. Both DTPA- and EDTA-extractable LREEs were significantly correlated to LREE concentrations in wheat roots and shoots. DTPA extractable LREEs were comparable to LREEs in wheat roots, however, the EDTA exctractable LREEs overestimated the LREE accumulation in wheat roots. Neither root nor shoot LREEs showed significant correlation with $\mathrm{CH}_{3} \mathrm{COOH}$ extractable LREEs, suggesting that the $\mathrm{CH}_{3} \mathrm{COOH}$ extraction method was not suitable for predicting LREE bioavailability. $\mathrm{CaCl}_{2}$ method was unable to estimate the LREE bioavailability due to poor data distribution in correlation analysis. Overall, DTPA extraction method was preferred to other extraction methods for estimating bioavailability of LREEs to wheat.
\end{abstract}

(C) 2007 Elsevier B.V. All rights reserved.

Keywords: Light rare earth elements; Extraction method; Bioavailability; Wheat; Field study; Soil properties

\section{Introduction}

Fertilizers containing rare earth elements (REEs) with predominant proportion $\mathrm{La}$ and $\mathrm{Ce}$ are widely used in agriculture in China in order to increase crop yields of some plant species, particularly if moisture is limited (Xu et al., 2002; Shtangeeva, 2004). Since 1990s, millions of tons of such fertilizers have been applied. As a result, REEs in China have been found to be accumulated in soils, crops, and enter the food chain (Chua et al., 1998; Wen et al., 2001). Others sources (sewage sludge, incinerator bottom ashes and rainwater) can also contribute to environmental contamination by REEs (Zhang et al., 2001; Zhang and Liu, 2004). The adverse health effect and potential detrimental environmental issue caused by REEs are concerned by environmental scientists. Possible

\footnotetext{
* Corresponding author. Tel.: +86 10 62923560; fax: +86 1062923563 .

E-mail address: xiaoquan@rcees.ac.cn (X.-Q. Shan).
}

health risks for humans could not be excluded and health status of children should be examined from health risk assessment perspective in rare earth mining areas (De Boer et al., 1996; Tong et al., 2004). High concentrations of REEs may cause significant damage to ecosystem (Barry and Meehan, 2000). Some studies also focused on the toxic effects of REEs to plants from occupational and environmental exposures and the longterm hazardous environment effects (Sax, 1984; Suzuki et al., 1992). To evaluate the ecotoxicological risks of REEs, the first step is to estimate the bioavailability of REEs.

REE bioavailability is measured by assessing the proportion of REEs that is accumulated by an organism or that can cause a biological response. It is the common concept nowadays that total concentration of metals in soils is not a good indicator of bioavailability, and a good tool for potential risk assessment neither (Qian et al., 1996; Chen et al., 1996). Extraction procedures using a selective chemical extractant, such as strong chelating agents, mild neutral salts, organic or inorganic acid 


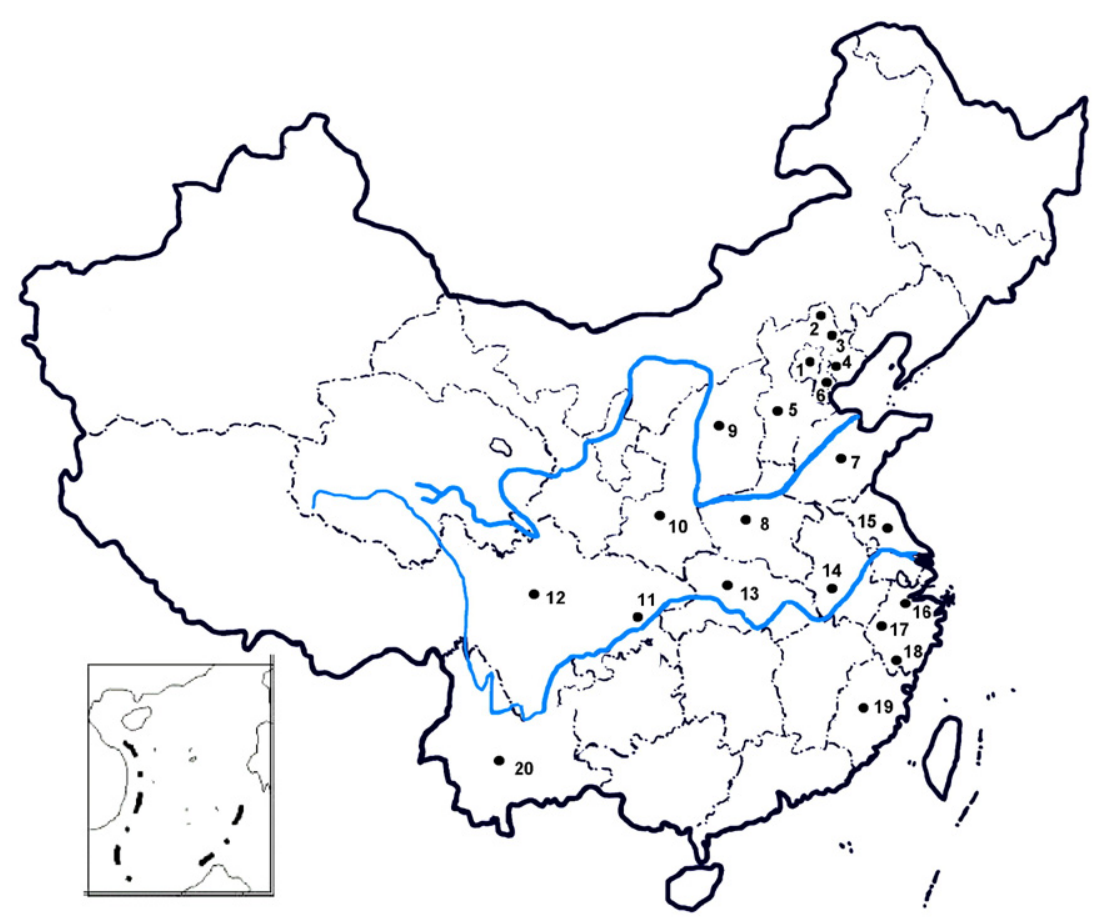

Fig. 1. Soil and wheat sampling locations. (1) Beijing, (2) Hebei 1, (3) Hebei 2, (4) Hebei 3, (5) Hebei 4, (6) Tianjin, (7) Shandong, (8) Henan, (9) Shanxi, (10) Sha'anxi, (11) Chongqing, (12) Sichuan, (13) Hubei, (14) Anhui, (15) Jiangsu, (16) Zhejiang 1, (17) Zhejiang 2, (18) Zhejiang 3, (19) Fujian, (20) Yunnan.

(Lu et al., 2003; Wang et al., 2003; Wang et al., 2004) could provide information on the potential mobility and bioavailability of REEs. Bioavailability of REEs depends on the chemical speciation of REEs in soils and plant species (Zhang and Shan, 2001; Hu et al., 2002; Wang et al., 2004). Shan et al. (2003) found that REEs in the labile rhizosphere soil solution, including free metal ions and inorganic and organic complexes, were mostly bioavailable. REEs in water soluble, exchangeable and carbonate bound fractions were significantly correlated with REE uptake by wheat (Wang et al., 2001) and alfalfa (Cao et al., 2000). $\mathrm{CaCl}_{2}$ and $\mathrm{CH}_{3} \mathrm{COOH}$ extracted REEs were reported to be best correlated with REE contents in shoots of wheat (Lu et al. 2003). $0.1 \mathrm{~mol}^{-1} \mathrm{HCl}$ gave a good estimate of the wheat available REEs in soils (Li et al. 2001). A mixture of malic and citric acids could be also used as a predictor of available REEs (Zhang et al. 2000). The above studies were inconsistent and made comparisons difficult. However, most of the results were obtained under greenhouse conditions. Extrapolation of the results to the field might be problematic due to the complicated growth conditions. Therefore, the aims of this work are (1) to identify which soil properties are mostly related to LREE bioavailability; (2) to search for the most efficient extraction method for evaluation of LREE bioavailability to wheat under field conditions by comparing EDTA, DTPA, $\mathrm{CaCl}_{2}$ and $\mathrm{CH}_{3} \mathrm{COOH}$ extraction methods.

\section{Materials and methods}

\subsection{Soil and wheat samples}

Twenty cultivated surface soils and the corresponding wheat seedlings from the same field were collected from 15 different
Chinese provinces during February 2005 (Fig. 1). Within each sampling unit, both soil and wheat subsamples were taken from several different locations (5-10 locations, depending on the uniformity and size of the sampling unit), and were mixed into one composite sample. Moist soils and wheat samples were preserved separately in polyethylene bags during transport to the laboratory. All wheat seedlings were cut to the size of $3-7 \mathrm{~cm}$ for

Table 1

Extraction procedures used in this study

\begin{tabular}{|c|c|c|c|}
\hline Extractant & Procedure & Fraction & Reference \\
\hline $\mathrm{CaCl}_{2}$ & $\begin{array}{l}2.00 \mathrm{~g} \text { soil was mixed with } \\
20 \mathrm{ml} 0.01 \mathrm{~mol} \mathrm{l}^{-1} \mathrm{CaCl}_{2} \\
\text { in a } 50 \mathrm{ml} \text { plastic centrifuge } \\
\text { tube, and shaken for } 3 \mathrm{~h}\end{array}$ & $\begin{array}{l}\text { Easily } \\
\text { exchangeable }\end{array}$ & $\begin{array}{l}\text { Novozamsky } \\
\text { et al. (1993) }\end{array}$ \\
\hline $\mathrm{CH}_{3} \mathrm{COOH}$ & $\begin{array}{l}1.00 \mathrm{~g} \text { soil was mixed with } \\
20 \mathrm{ml} 0.11 \mathrm{~mol} \mathrm{l}^{-1} \text { acetic acid } \\
\text { in a } 50 \mathrm{ml} \text { plastic centrifuge } \\
\text { tube, and shaken for } 16 \mathrm{~h}\end{array}$ & $\begin{array}{l}\text { Exchangeable } \\
\text { and carbonate } \\
\text { bound }\end{array}$ & $\begin{array}{l}\text { Ure et al. } \\
\text { (1993) }\end{array}$ \\
\hline EDTA & $\begin{array}{l}2.00 \mathrm{~g} \text { soil was mixed with } \\
20 \mathrm{ml} 0.05 \mathrm{~mol}^{-1} \text { EDTA } \\
\text { and its } \mathrm{pH} \text { was adjusted with } \\
\text { ammonia solution to } 7.0 \text { in a } \\
50 \mathrm{ml} \text { plastic centrifuge tube, } \\
\text { and the suspension was shaken } \\
\text { for } 1 \mathrm{~h}\end{array}$ & $\begin{array}{l}\text { Organically } \\
\text { bound and } \\
\text { metals } \\
\text { occluded in } \\
\text { oxides and } \\
\text { secondary } \\
\text { clay minerals } \\
\text { in part }\end{array}$ & $\begin{array}{l}\text { Wear and } \\
\text { Evans } \\
(1968)\end{array}$ \\
\hline DTPA & $\begin{array}{l}10.0 \mathrm{~g} \text { soil was mixed with } \\
20 \mathrm{ml} 0.005 \mathrm{~mol} \mathrm{l}^{-1} \\
\mathrm{DTPA}+0.01 \mathrm{~mol} \mathrm{l}^{-1} \\
\mathrm{CaCl}_{2}+0.01 \mathrm{~mol} \mathrm{l}^{-1} \mathrm{TEA}, \mathrm{pH} \\
\text { of suspension was adjusted to } \\
\mathrm{pH} 7.3 \text { in a } 50 \mathrm{ml} \text { plastic } \\
\text { centrifuge tube, and shaken } \\
\text { for } 2 \mathrm{~h}\end{array}$ & $\begin{array}{l}\text { Iron and } \\
\text { manganese } \\
\text { oxides bound }\end{array}$ & $\begin{array}{l}\text { Lindsay and } \\
\text { Norvell } \\
\text { (1978) }\end{array}$ \\
\hline
\end{tabular}


Table 2

Selected properties of soils and total LREE contents in soils

\begin{tabular}{|c|c|c|c|c|c|c|c|c|c|c|}
\hline \multirow[t]{2}{*}{ Site } & \multirow[t]{2}{*}{$\mathrm{pH}$} & \multirow{2}{*}{$\frac{\mathrm{CEC}}{\mathrm{me} / 100 \mathrm{~g}}$} & \multirow{2}{*}{$\frac{\mathrm{SOM}}{\%}$} & \multicolumn{2}{|c|}{$\mathrm{Fe}(\mathrm{g} / \mathrm{kg})$} & \multirow{2}{*}{$\frac{\text { CryMn }}{\mathrm{g} / \mathrm{kg}}$} & \multicolumn{4}{|c|}{ Total LREEs (mg/kg) } \\
\hline & & & & CryFe & AmorFe & & $\mathrm{La}$ & $\mathrm{Ce}$ & $\operatorname{Pr}$ & $\mathrm{Nd}$ \\
\hline Beijing & 7.40 & 12.50 & 2.96 & 2.02 & 0.76 & 0.12 & 27.12 & 45.76 & 7.65 & 21.54 \\
\hline Hebei 1 & 7.48 & 12.81 & 1.56 & 3.38 & 1.10 & 0.25 & 9.89 & 23.86 & 2.69 & 9.57 \\
\hline Hebei 2 & 7.19 & 8.34 & 1.88 & 1.85 & 0.93 & 0.12 & 9.95 & 24.01 & 2.70 & 9.63 \\
\hline Hebei 3 & 5.92 & 14.89 & 2.11 & 4.10 & 2.07 & 0.19 & 4.65 & 14.15 & 1.84 & 4.68 \\
\hline Hebei 4 & 7.59 & 10.82 & 2.91 & 1.30 & 0.44 & 0.10 & 20.82 & 34.81 & 4.43 & 17.29 \\
\hline Tianjin & 7.24 & 14.29 & 1.66 & 2.47 & 1.01 & 0.22 & 13.55 & 38.29 & 4.62 & 14.19 \\
\hline Shandong & 7.31 & 9.52 & 1.97 & 1.62 & 0.85 & 0.11 & 25.67 & 43.82 & 6.20 & 20.56 \\
\hline Henan & 7.38 & 18.56 & 1.28 & 2.24 & 0.95 & 0.17 & 26.35 & 45.52 & 6.75 & 21.42 \\
\hline Shanxi & 7.34 & 8.12 & 1.12 & 1.22 & 0.31 & 0.11 & 25.52 & 43.84 & 6.21 & 21.05 \\
\hline Sha'anxi & 6.18 & 16.91 & 1.14 & 5.63 & 0.94 & 0.65 & 33.53 & 56.48 & 11.54 & 25.35 \\
\hline Chongqing & 6.98 & 27.30 & 1.1 & 5.13 & 0.97 & 0.19 & 35.68 & 63.24 & 11.15 & 28.03 \\
\hline Sichuan & 6.74 & 18.95 & 4.46 & 4.42 & 2.39 & 0.12 & 33.86 & 59.54 & 11.09 & 26.69 \\
\hline Hubei & 5.30 & 7.10 & 1.81 & 6.18 & 2.93 & 0.93 & 5.23 & 9.92 & 1.74 & 5.55 \\
\hline Anhui & 5.98 & 14.25 & 2.51 & 8.42 & 6.18 & 0.16 & 34.38 & 60.09 & 12.76 & 26.76 \\
\hline Jiangsu & 7.36 & 7.55 & 1.1 & 1.37 & 0.49 & 0.11 & 23.33 & 39.31 & 5.86 & 18.90 \\
\hline Zhejiang 1 & 5.30 & 6.99 & 2.18 & 2.17 & 1.42 & 0.09 & 30.77 & 60.5 & 11.61 & 22.27 \\
\hline Zhejiang 2 & 7.25 & 9.96 & 3.48 & 2.93 & 1.32 & 0.42 & 18.18 & 43.18 & 6.41 & 14.41 \\
\hline Zhejiang 3 & 5.24 & 18.16 & 3.88 & 3.43 & 2.89 & 0.05 & 27.39 & 56.01 & 10.70 & 22.80 \\
\hline Fujian & 6.82 & 6.92 & 2.13 & 1.69 & 1.10 & 0.06 & 23.86 & 45.19 & 8.59 & 17.07 \\
\hline Yunnan & 6.06 & 6.65 & 1.30 & 0.80 & 0.38 & 0.05 & 7.05 & 16.06 & 3.26 & 6.50 \\
\hline Medium value of world soil & & & & & & & 40 & 50 & 7 & 35 \\
\hline Range of world soil & & & & & & & $7-180$ & $3-170$ & $3-12$ & $4-63$ \\
\hline
\end{tabular}

$\mathrm{CEC}=$ cation exchange capacity.

$\mathrm{SOM}=$ soil organic matter.

$\mathrm{CryFe}=$ crystalline $\mathrm{Fe}$ oxide contents.

$\mathrm{AmorFe}=$ amorphous $\mathrm{Fe}$ oxide contents.

CryMn $=$ crystalline $\mathrm{Mn}$ oxide contents.

roots and $11-21 \mathrm{~cm}$ for shoots. Roots and shoots were firstly rinsed thoroughly with tap water and subsequently with deionized water, and finally with ultrasonic-assisted washing for extra $20 \mathrm{~min}$ to remove the fine adhering soil particles. After washing, wheat shoots and roots were dried at $60^{\circ} \mathrm{C}$ for $48 \mathrm{~h}$ and separately finely ground before analysis. Subsamples of soils were air-dried and small pieces of broken roots and any other extraneous materials were carefully removed, prior to sieving $<1 \mathrm{~mm}$ using a nylon fiber sieve and stored for subsequent analysis of soil characteristics. The remaining portions of soils were refrigerated at $-18{ }^{\circ} \mathrm{C}$ prior for measuring soil humidity and extraction. Soil organic matter (SOM) content was determined using the Walkley-Black procedure (Nelson and Sommers, 1982). Soil pH was measured at a soil to $0.01 \mathrm{~mol} \mathrm{l}^{-1}$ $\mathrm{CaCl}_{2}$ solution ratio of $1: 5(\mathrm{w} / \mathrm{v})$. CEC was determined by standard methods (Rhoades, 1982). Cation exchange capacity (CEC) of the soils with $\mathrm{pH}<7.0$ was determined by the $\mathrm{BaCl}_{2}$ method, while the $\mathrm{CEC}$ of soils with $\mathrm{pH}>7.0$ was determined by the $\mathrm{CH}_{3} \mathrm{COONa}$ method. Amorphous Fe oxide was extracted by shaking $1.00 \mathrm{~g}$ of soil in $30 \mathrm{ml}$ of acidified ammonium oxalate buffer $\left(0.175 \mathrm{~mol} \mathrm{l}^{-1}\left(\mathrm{NH}_{4}\right)_{2} \mathrm{C}_{2} \mathrm{H}_{4}+0.1 \mathrm{~mol} \mathrm{l}^{-1} \mathrm{H}_{2} \mathrm{C}_{2} \mathrm{O}_{4}, \mathrm{pH}\right.$ 3.0) for $2 \mathrm{~h}$ (Loeppert and Inskeep, 1996). Crystalline Fe and $\mathrm{Mn}$ oxides were determined by the oxalate-ascorbic acid extraction method of Shuman (Shuman, 1982).

\subsection{Extraction procedure}

Field moist soils were subjected to all of the extraction procedures in order to avoid metal speciation change during drying process. The detailed operations and nominal target fractions in soils were described briefly in Table 1. For all extraction procedures, after shaking, the suspensions were centrifuged at $7000 \mathrm{~g}$ for $20 \mathrm{~min}$ and the supernatant was filtered through a disposable $0.45 \mu \mathrm{m}$ cellulose acetate membrane filter prior to LREE determination. All extractions including blanks were carried out in triplicate.

Table 3

Total contents of LREEs in wheat $\left(\mathrm{mg} \mathrm{kg}^{-1} \mathrm{DM}\right)$ and the correlation between LREE in wheat roots and shoots

\begin{tabular}{|c|c|c|c|c|c|c|}
\hline \multirow[t]{2}{*}{ Element } & \multicolumn{2}{|l|}{ In roots } & \multicolumn{2}{|l|}{ In shoots } & \multirow[t]{2}{*}{ Equations } & \multirow[t]{2}{*}{$R$} \\
\hline & Range & Mean & Range & Mean & & \\
\hline $\mathrm{La}$ & $636-10,642$ & 3171 & $114-7209$ & 1320 & Shoot $-\mathrm{La}=0.38 \times$ Root $-\mathrm{La}$ & $0.642 * *$ \\
\hline $\operatorname{Pr}$ & $152-2510$ & 801 & $25-1730$ & 306 & Shoot $-\mathrm{Pr}=0.40 \times$ Root $-\mathrm{La}$ & $0.642 * *$ \\
\hline $\mathrm{Nd}$ & $578-10,234$ & 3126 & $103-6909$ & 1205 & Shoot $-\mathrm{Nd}=0.41 \times$ Root $-\mathrm{La}$ & $0.668^{* * *}$ \\
\hline
\end{tabular}

$R=$ the correlation coefficient $* *$ and $* * *=$ the probability level of $p<0.01$ and $p<0.001$, respectively. 
Table 4

Linear correlation coefficients $(R)$ between LREE concentrations in wheat shoots and roots and soil properties $(n=20)$

\begin{tabular}{lllllllr}
\hline & Element & $\mathrm{pH}$ & $\mathrm{CEC}$ & $\mathrm{SOM}$ & CryFe & AmorFe & CryMn \\
\hline Root & $\mathrm{La}$ & $-0.73^{* * *}$ & 0.17 & 0.18 & 0.44 & $0.57^{* *}$ & 0.03 \\
& $\mathrm{Ce}$ & $-0.70^{* * *}$ & 0.16 & 0.21 & 0.34 & $0.50^{*}$ & 0.02 \\
& $\mathrm{Pr}$ & $-0.73^{* * *}$ & 0.19 & 0.19 & 0.39 & $0.50^{*}$ & 0.03 \\
& $\mathrm{Nd}$ & $-0.73^{* * *}$ & 0.19 & 0.21 & 0.39 & $0.51^{*}$ & 0.02 \\
Shoot & $\mathrm{La}$ & -0.38 & 0.10 & 0.40 & 0.09 & 0.41 & -0.20 \\
& $\mathrm{Ce}$ & -0.40 & 0.09 & 0.42 & 0.09 & 0.39 & -0.16 \\
& $\mathrm{Pr}$ & -0.38 & 0.12 & 0.41 & 0.09 & 0.41 & -0.19 \\
& $\mathrm{Nd}$ & -0.41 & 0.12 & 0.41 & 0.11 & 0.43 & -0.19
\end{tabular}

$*$, ** and $* * *=$ the probability level of $p<0.05, p<0.01$ and $p<0.001$, respectively.

$\mathrm{CEC}=$ cation exchange capacity.

$\mathrm{SOM}=$ soil organic matter.

CryFe $=$ crystalline $\mathrm{Fe}$ oxide contents.

AmorFe $=$ amorphous $\mathrm{Fe}$ oxide contents.

CryMn $=$ crystalline Mn oxide contents.

\subsection{Determination of LREEs in soils and plants}

Total LREE concentrations in soils, and in wheat shoots and roots were determined by inductively coupled plasma-mass spectrometry (ICP-MS) (Thermo Electron Company, USA) with $\mathrm{Rh}$ as an internal standard after digestion with $3 \mathrm{ml}$ of $\mathrm{HNO}_{3}-\mathrm{HClO}_{4}-\mathrm{HF}(1: 1: 1, \mathrm{v} / \mathrm{v})$ in PTFE vessel under highpressure conditions (Zhang and Shan, 1997). For quality control of low levels of LREEs in wheat a certified reference material (GBW 08505 tea leaves) was used throughout this work. The data determined by this method were within the certified range of each metal (data not shown), indicating that the plant LREE concentrations determined in this work were reliable. LREE concentrations in soil solution obtained from extraction methods were also determined by ICP-MS.

\subsection{Statistical analysis}

Statistical analyses were performed using SPSS 11.5 for Windows (SPSS Inc., USA). Linear correlation analysis was performed for soils to visualize the relationship between wheat LREE concentrations in shoots and roots, and soil extractable LREEs or soil properties.

\section{Results and discussion}

\subsection{LREEs in soils and wheat, and extractable LREEs from soils}

The total LREE contents in soils varied considerably, ranging from 4.65-35.68 (La), 9.92-63.24 (Ce), 1.74-12.76 (Pr), and $4.68-28.03 \mathrm{mg} \mathrm{kg}^{-1}(\mathrm{Nd})$ (Table 2). The contents of each LREEs followed the order $\mathrm{Ce}>\mathrm{La} \geq \mathrm{Nd}>\mathrm{Pr}$. No significant contamination of LREEs in soils was found because most of the total LREE contents in the studied soils were in the background range of REEs in world soils. Among them $\mathrm{Ce}$ and Pr contents in six and eight soils were higher than the medium values of world soils, respectively. Both $\mathrm{La}$ and $\mathrm{Nd}$ contents of all the studied soils were below the medium values of world soils.
Total concentrations of LREEs in wheat roots were higher than those in shoots (Table 3). Significant correlation was observed between LREE contents in roots and shoots in this work. The coefficients between REE contents in shoots and roots ranged from 0.38 to 0.42 , indicating that LREE accumulation ratio of shoots to roots were about $38-42 \%$ by mean.

The extractable LREEs by the four extractants followed the order EDTA $>$ DTPA $>\mathrm{CH}_{3} \mathrm{COOH}>\mathrm{CaCl}_{2}$, which were in the range of 21.2-32.7\% (EDTA), 6.9-11.6\% (DTPA), 0.53-0.87\% $\left(\mathrm{CH}_{3} \mathrm{COOH}\right)$, and less than $0.1 \%\left(\mathrm{CaCl}_{2}\right)$ of total LREEs in soils. The reasons for this order were mainly ascribed to their different extractability. EDTA is a strong chelating reagent, which has been reported to extract labile and non-labile metals, including exchangeable and weakly organically bound fractions (Bermond et al., 1998). Iron and manganese oxides are potentially extracted from acidic soils by DTPA (O’Connor, 1988). The high concentration of acetic acid can extract weakly organically bound metals (Payà-Pèrez et al., 1993) and most of calcium and mineral bound metals (Whalley and Grant, 1994). $\mathrm{CaCl}_{2}$ is mainly able to extract easily exchangeable metals.

\subsection{Relationship between soil properties and bioavailability of LREES}

Linear correlation analysis was performed in order to define the relationship between LREE concentrations in wheat and soil properties (Table 4). LREE concentrations in shoots were not correlated $(p>0.05)$ to any soil variables, suggesting that shoot accumulation of LREEs was not influenced by soil properties. Negative correlations were found between soil $\mathrm{pH}$ and root LREE concentrations, whereas the amorphous Fe oxide

Table 5

Linear correlation coefficients $(R)$ between extractable LREEs and soil properties

\begin{tabular}{llllllll}
\hline Extractant & Element & $\mathrm{pH}$ & CEC & SOM & CryFe & AmorFe & CryMn \\
\hline DTPA & $\mathrm{La}$ & $-0.86^{* * *}$ & 0.08 & 0.32 & $0.54^{*}$ & $0.74^{* * *}$ & 0.10 \\
& $\mathrm{Ce}$ & $-0.84^{* * *}$ & 0.04 & 0.33 & 0.42 & $0.64 * *$ & 0.12 \\
& $\mathrm{Pr}$ & $-0.82^{* * *}$ & 0.15 & 0.37 & $0.48^{*}$ & $0.68^{* * *}$ & 0.07 \\
& $\mathrm{Nd}$ & $-0.82^{* * *}$ & 0.16 & 0.36 & $0.48^{*}$ & $0.67^{* * *}$ & 0.06 \\
EDTA & $\mathrm{La}$ & -0.39 & 0.03 & 0.44 & 0.32 & $0.84^{* * *}$ & 0.11 \\
& $\mathrm{Ce}$ & $-0.64^{* *}$ & 0.07 & 0.38 & 0.43 & $0.84 * * *$ & 0.12 \\
& $\mathrm{Pr}$ & $-0.45^{*}$ & 0.08 & $0.51^{*}$ & 0.36 & $0.79^{* * *}$ & 0.10 \\
& $\mathrm{Nd}$ & $-0.47^{*}$ & 0.13 & $0.52^{*}$ & 0.39 & $0.78^{* * *}$ & 0.12 \\
$\mathrm{CaCl}_{2}$ & $\mathrm{La}$ & $-0.70^{* * *}$ & 0.07 & 0.37 & 0.16 & 0.40 & 0.03 \\
& $\mathrm{Ce}$ & $-0.68^{* * *}$ & 0.07 & 0.37 & 0.13 & 0.35 & 0.00 \\
& $\mathrm{Pr}$ & $-0.69^{* * *}$ & 0.06 & 0.35 & 0.12 & 0.35 & 0.02 \\
& $\mathrm{Nd}$ & $-0.71^{* * *}$ & 0.04 & 0.33 & 0.12 & 0.34 & 0.00 \\
$\mathrm{CH}_{3} \mathrm{COOH}$ & $\mathrm{La}$ & 0.15 & 0.29 & 0.12 & 0.26 & 0.08 & 0.25 \\
& $\mathrm{Ce}$ & 0.02 & 0.28 & 0.06 & 0.17 & 0.02 & 0.21 \\
& $\mathrm{Pr}$ & 0.13 & 0.26 & 0.11 & 0.23 & 0.04 & 0.27 \\
& $\mathrm{Nd}$ & 0.16 & 0.26 & 0.15 & 0.25 & 0.06 & 0.28 \\
\hline
\end{tabular}

$*$, ** and $* * *=$ the probability level of $p<0.05, p<0.01$ and $p<0.001$, respectively.

$\mathrm{CEC}=$ cation exchange capacity.

$\mathrm{SOM}=$ soil organic matter.

$\mathrm{CryFe}=$ crystalline $\mathrm{Fe}$ oxide contents .

AmorFe $=$ amorphous $\mathrm{Fe}$ oxide contents.

CryMn $=$ crystalline $\mathrm{Mn}$ oxide contents. 
Table 6

Linear correlation coefficients $(R)$ between LREE concentrations in wheat shoots and roots and LREEs extracted by different extraction methods $(n=20)$

\begin{tabular}{llllll}
\hline & Element & $\mathrm{CaCl}_{2}$ & $\mathrm{CH}_{3} \mathrm{COOH}$ & EDTA & DTPA \\
\hline Root & $\mathrm{La}$ & $0.76^{* * *}$ & 0.09 & $0.64 * *$ & $0.91^{* * *}$ \\
& $\mathrm{Ce}$ & $0.77^{* * *}$ & 0.25 & $0.73^{* * *}$ & $0.83^{* * *}$ \\
& $\mathrm{Pr}$ & $0.80^{* * *}$ & 0.11 & $0.69 * * *$ & $0.90^{* * *}$ \\
& $\mathrm{Nd}$ & $0.82^{* * *}$ & 0.05 & $0.71^{* * *}$ & $0.91 * * *$ \\
\multirow{5}{*}{ Shoot } & $\mathrm{La}$ & $0.80^{* * *}$ & 0.33 & $0.58^{* *}$ & $0.67 * *$ \\
& $\mathrm{Ce}$ & $0.81^{* * *}$ & 0.38 & $0.66^{* *}$ & $0.77^{* * *}$ \\
& $\mathrm{Pr}$ & $0.79 * * *$ & 0.36 & $0.68^{* * *}$ & $0.75^{* * *}$ \\
& $\mathrm{Nd}$ & $0.79 * * *$ & 0.31 & $0.70^{* * *}$ & $0.78^{* * *}$ \\
\hline
\end{tabular}

$* *$ and $* * *=$ the probability level of $p<0.01$ and $p<0.001$, respectively.

contents were positively correlated with root LREEs. However, in the present work, CEC, SOM and crystalline Fe and Mn oxide contents had little effect on the bioavailability of LREEs. The adverse effect of $\mathrm{pH}$ on root LREE contents was consistent with the general expectation of greater bioavailability of LREEs at lower soil $\mathrm{pH}$, since LREEs would be precipitated and less released from soils as the soil $\mathrm{pH}$ increased (Cao et al., 2001; Zhang and Shan, 2001). Amorphous Fe was the main factor controlling the adsorption capacities of LREEs in soils (Liu and Ran, 1993). Cao et al. (2001) reported that LREE release might originate from dissolution of $\mathrm{Fe}$ and $\mathrm{Mn}$ oxyhydroxides under reduction and lower $\mathrm{pH}$ conditions. Thus, the more amorphous
Fe contents, the more LREEs in soils and the bigger bioavailable pool of LREEs.

\subsection{Relationship between soil properties and extractable LREEs by various methods}

Linear correlation analysis between the extractable LREEs and soil properties are shown in Table 5. This work verified that soil $\mathrm{pH}, \mathrm{Fe}$ oxide and SOM contents could influence LREE extractability of different extractants. Both DTPA- and EDTAextractable LREEs were significantly negatively correlated with soil $\mathrm{pH}$ and positively correlated with amorphous $\mathrm{Fe}$ oxide contents, suggesting that DTPA and EDTA were able to extract more LREEs in the soils with low $\mathrm{pH}$ and high amorphous Fe oxide contents. DTPA-extractable LREEs also correlated with soil crystalline Fe oxide contents with the exception of $\mathrm{Ce}$, and the correlation coefficients were about 0.50 , which were much lower than those between DTPA- and EDTA-extractable LREEs and amorphous $\mathrm{Fe}$ oxide contents. In addition, EDTAextractable $\mathrm{Pr}$ and $\mathrm{Nd}$ were significantly related to SOM contents. Negative correlation was also found between soil $\mathrm{pH}$ and the $\mathrm{CaCl}_{2}$-extractable LREEs. By contrast, $\mathrm{CH}_{3} \mathrm{COOH}$ extractable LREEs showed no correlation with any soil properties. The inverse effect of soil $\mathrm{pH}$ on metal extractability was always obtained, which may partly attribute to the increasing displacement

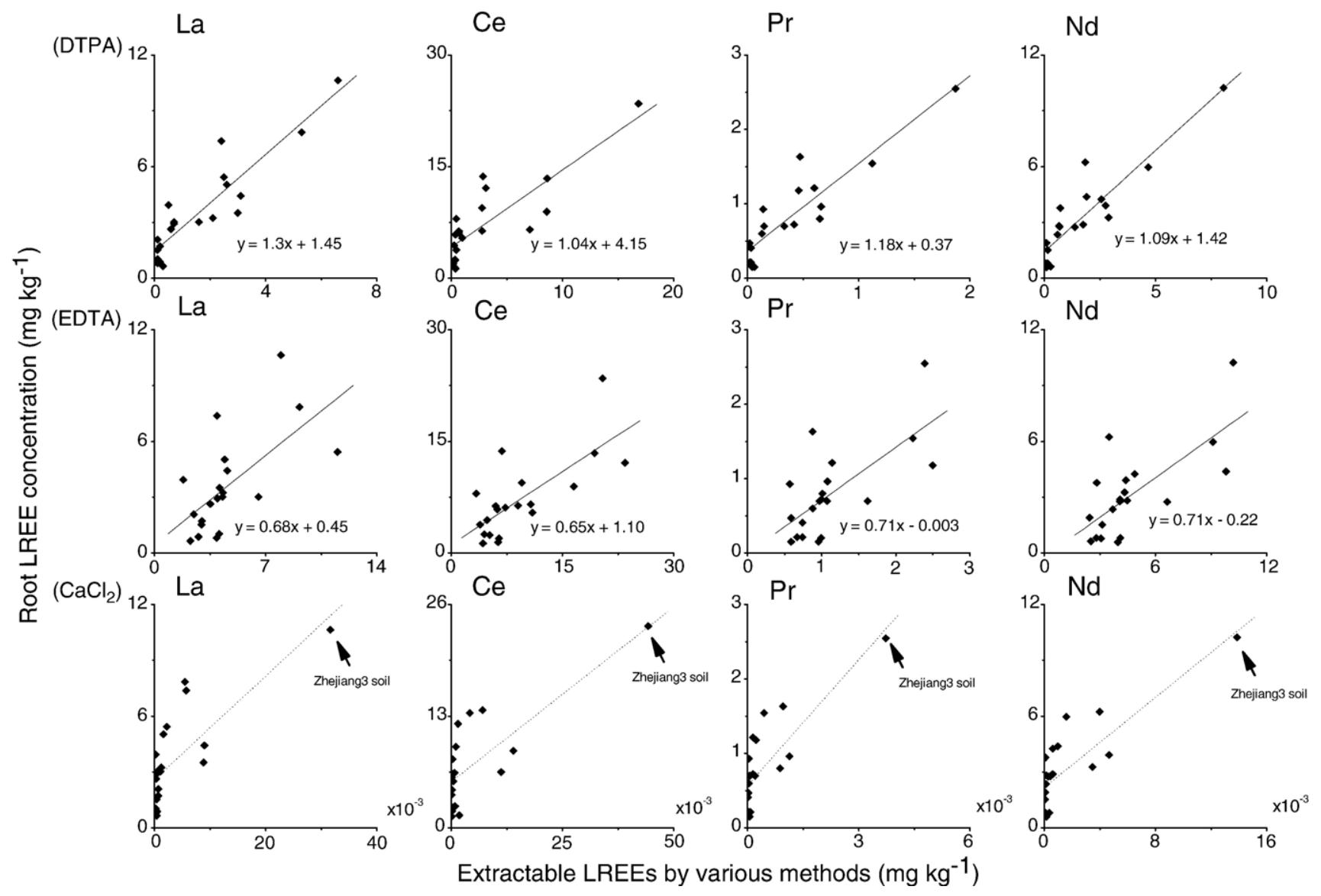

Fig. 2. Linear correlation between accumulated LREEs in wheat roots and extracted LREEs by various extraction methods. 
of adsorbed metal ions into extractant solution (or soil solution in real situations) by $\mathrm{H}^{+}$ions as acidity increases (Rieuwerts et al., 2006).

\subsection{Evaluation of LREE bioavailability using various extraction methods}

Linear correlation analysis demonstrated that the concentrations of LREEs in both wheat roots and shoots were significantly correlated to DTPA-, EDTA- and $\mathrm{CaCl}_{2}$-extractable LREEs from soils (Table 6). The correlation coefficients (r) between accumulated LREEs in roots and extractable LREEs by DTPA method (ranging of $0.83-0.91$ ) were the highest among these extraction methods, followed by $\mathrm{CaCl}_{2}$ (ranging of $0.77-0.82$ ) and EDTA methods (ranging of 0.64-0.73). As far as the relationship between the extractable REEs from soils and REEs in shoots is concerned that three extraction methods had quite similar correlation coefficients although the $\mathrm{CaCl}_{2}$ method seems to be slightly better. In contrast, no significant relationship was found between $\mathrm{CH}_{3} \mathrm{COOH}$ extractable LREEs and LREE contents in wheat roots or shoots, suggesting that $\mathrm{CH}_{3} \mathrm{COOH}$ method was not suitable to predict LREE bioavailability to wheat under field conditions.

Many studies have shown that chemical extraction procedures can measure the metals in soil pools potentially available for plant uptake and/or accumulation (Kennedy et al., 1997). Single extraction method is based on the assumption that there is a relationship between the extractable fraction of metals and the bioavailability of metals to plants, i.e., a good correlation indicated that a certain fraction of total metal in the soils was available to plants (Wang et al., 2004).

Generally, a comparison of the $r$-values of linear correlation analysis for extraction methods does not suggest one or the other to be a better predictor of crop accumulation (McBride et al., 2003). The reliability of a linear correlation analysis is dependent on good distribution of samples across the interval of interest. Thus single linear correlation between root LREE concentrations (y axis) and extractable LREEs from soils ( $x$-axis) were plotted in Fig. 2. Inspection of the data, however, revealed that the correlation of $\mathrm{CaCl}_{2}$ extraction method was biased by the dominating effect of Zhejiang3 soil on the correlation analysis. Most of the outlier data points were near the $y$-axis in Fig. $2-\mathrm{CaCl}_{2}\left(\mathrm{CaCl}_{2}\right.$ extractable $\mathrm{La}<0.01 \mathrm{mg} \mathrm{kg}^{-1}$ ). A similar pattern of data distribution was observed for $\mathrm{Ce}, \mathrm{Pr}$ and $\mathrm{Nd}$ for $\mathrm{CaCl}_{2}$ extraction method as well. These were mainly due to the extremely low extractable LREEs by $\mathrm{CaCl}_{2}$, resulting in small variance of extractability of LREEs among most soils. Thus $\mathrm{CaCl}_{2}$ method seemed not to be a good approach for assessing LREE bioavailability to wheat. By contrast, the relationships obtained by both DTPA and EDTA methods revealed a monotonic trend that was dependent on good distribution of data. The slope values of regression equations that indicated the average ratio of extracted LREE quantity $\left(\mathrm{mg} \mathrm{kg}^{-1}\right)$ to root accumulated LREEs $\left(\mathrm{mg} \mathrm{kg}^{-1}\right)$ obtained by DTPA method were close to 1 (ranged from 1.04 to 1.30) (Fig. 2), demonstrating that the accumulated LREEs in wheat roots is comparable to the DTPA-extractable pool from soils. While the correlation slopes of the EDTA method were from
0.65 to 0.71 , indicating that EDTA-extractable LREEs would overestimate the accumulation of LREEs in wheat roots.

Ideally, a good method for predicting LREE bioavailability should mimic the root-soil interactions as closely as possible. For the DTPA method, the strongest soil factors controlling the extractability of LREEs were soil $\mathrm{pH}$ and amorphous $\mathrm{Fe}$ oxide contents, which were the most important factors influencing the LREE concentrations in roots (Tables 4 and 5). It might indicate that DTPA extraction could mostly reflect the soil property-related factors that modulate wheat uptake of LREEs. This deduction was further supported by the results that DTPA-extractable LREEs were best correlated to wheat root LREEs. On the contrary, $\mathrm{CH}_{3} \mathrm{COOH}$ extractability could hardly be affected by soil properties (Table 5), and no significant relations were obtained between extractable LREEs by $\mathrm{CH}_{3} \mathrm{COOH}$ and root LREE contents.

In previous greenhouse works, Zhang et al. (2000) found that $\mathrm{CH}_{3} \mathrm{COOH}$ extraction was a poor indicator of REE availability to wheat. While the LREE fraction extracted by $\mathrm{CH}_{3} \mathrm{COOH}$ was also reported to correlate significantly with LREE contents in both roots and shoots of wheat, and this fraction represented the bioavailable pool after rare earth fertilizer application (Zhang and Shan, 2001). These contradictions really reflected the complication and uncertainty of REE bioavailability. The reason for this is probably due to the so called residence time effect or ageing effect, which significantly influenced the fractionation of exogenous metals in soils (Lu et al., 2005). Metals were possibly transformed from easily extractable fractions to more stable fractions during the ageing processes, thus became less bioavailable with increasing residence time in soils. Hence any acceptable extraction method for assessing bioavailability of LREEs should be tested under field conditions. In addition, soils studied in this work were not significantly contaminated by LREEs, more detailed field study is needed to test whether DTPA and EDTA methods still remain acceptable for predicting LREE bioavailability in LREE-contaminated soils.

\section{Conclusion}

LREE accumulation in wheat roots were influenced by soil $\mathrm{pH}$ and amorphous Fe oxide contents in soils, while SOM, CEC, crystalline Fe and Mn oxide contents had little effects. Shoot LREEs were independent of soil properties. Based on the relationship between the extractable REEs and REEs in wheat or soil properties one may conclude that the DTPA method best reflected soil-wheat root interactions as soil properties influenced the uptake of LREEs, thus the DTPA method was the most efficient approach for evaluation of LREE bioavailability. EDTA method was also a good approach for assessing bioavailability of LREEs to wheat, although the extractable LREEs by EDTA always overestimated the accumulation of LREEs in wheat roots. $\mathrm{CH}_{3} \mathrm{COOH}$ and $\mathrm{CaCl}_{2}$ methods seemed not a good choice of estimating bioavailability of LREEs to wheat.

\section{Acknowledgements}

This work was funded by the National Natural Science Foundation of China (Grant nos.20237010). 


\section{References}

Barry, M.J., Meehan, B.J., 2000. The acute and chronic toxicity of lanthanum to Daphnia carinata. Chemosphere 41, 1669-1674.

Bermond, A., Yousfi, I., Ghestem, J.P., 1998. Kinetic approach to the chemical speciation of trace metals in soils. Analyst 123, 785-789.

Cao, X.D., Wang, X.R., Zhao, G.W., 2000. Assessment of the bioavailability of rare earth elements in soils by chemical fraction and multiple regression analysis. Chemosphere 40, 23-28.

Cao, X.D., Chen, Y., Wang, X.R., Deng, X.H., 2001. Effects of redox potential and $\mathrm{pH}$ value on the release of rare earth elements from soil. Chemosphere $41,655-661$.

Chen, B., Shan, X.Q., Qian, J., 1996. Bioavailability index for quantitative evaluation of plant availability of extractable soil trace elements. Plant Soil $186,275-283$

Chua, H., Zhao, Y.G., Kwang, Y.H., Liu, Q.Y., Liu, X.H., 1998. Accumulation of environmental residues of rare earth elements in sugarcane. Environ. Int. 24, 287-291.

De Boer, J.L.M., Verweij, W., van der Velde-Koerts, T., Mennes, W., 1996. Levels of rare earth elements in Dutch drinking water and its sources. Determination by inductively coupled plasma mass spectrometry and toxicological implications. A pilot study. Water Res. 30, 190-198.

Hu, X., Ding, Z., Chen, Y., Wang, X., Dai, L., 2002. Bioaccumulation of lanthanum and cerium and their effects on the growth of wheat (Triticum aestivum $L$.) seedlings. Chemosphere 48, 621-629.

Kennedy, V.H., Sanchez, A.L., Oughton, D.H., 1997. Use of single and sequential chemical extractants to assess radionuclide and heavy metal availability from soils for root uptake. Analyst 122, 89R-100R.

Lindsay, W.L., Norvell, W.A., 1978. Development of a DTPA soil test for zinc, iron, manganese, and copper. Soil Sci. Soc. Am. J. 42, 421-428.

Li, F.L., Shan, X.Q., Zhang, S.Z., 2001. Evaluation of single extractants for assessing plant availability of rare earth elements in soil. Commun. Soil Sci. Plant Ana. 32, 2577-2587.

Liu, Z., Ran, Y., 1993. Adsorption and desorption of rare earth elements on soil and oxides. Acta Environ. Sci. 13, 288-293.

Loeppert, R.L., Inskeep, W.P., 1996. In: Sparks, D.L., et al. (Ed.), Methods of Soil Analysis, Part 3: Chemical Methods. Soil Science Society of America, Inc., Madison, WI, USA, pp. 639-664.

Lu, A.X., Zhang, S.Z., Shan, X.Q., Wang, S.X., Wang, Z.W., 2003. Application of microwave extraction for the evaluation of bioavailability of rare earth elements in soils. Chemosphere 53, 1067-1075.

Lu, A.X., Zhang, S.Z., Shan, X.Q., 2005. Time effect on the fractionation of heavy metals in soils. Geoderma 125, 225-234.

McBride, M.B., Nibarger, E.A., Richards, B.K., Steenhuis, T., 2003. Trace metal accumulation by red clover grown on sewage sludge-amended soils and correlation to Mehlich 3 and calcium chloride-extractable metals. Soil Sci. $168,29-38$.

Nelson, D.W., Sommers, D., 1982. Total carbon, organic carbon, and organic matter, In: Page, A.L., et al. (Ed.), Methods of Soil Analysis: Total Carbon, Organic Carbon, and Organic Matter, Part 2, 2nd ed. ASA and SSSA, Madison, WI, pp. 539-579.

Novozamsky, I., Lexmond, Th.M., Houba, V.J.G., 1993. A single extraction procedure of soil for evaluation of uptake of some heavy metals by plants. Int. J. Environ. Anal. Chem. 51, 47-58.

O'Connor, G.A., 1988. Use and misuse of the DTPA soil test. J. Environ. Qual. $17,715-718$.

Payà-Pèrez, A., Sala, J., Mousty, F., 1993. Comparison of ICP-AES and ICP-MS for the analysis of trace elements in soil extracts. Int. J. Environ. Anal. Chem. 51, 223-230.

Qian, J., Shan, X.Q., Wang, Z.J., Tu, Q., 1996. Distribution and plant availability of heavy metals in different particle-size fractions of soil. Sci. Total Environ. 187, 131-141.

Rhoades, J.D., 1982. Cation-exchange capacity, In: Page, A.L. (Ed.), Methods of Soil Analysis, Part 2, 2nd ed. American Society of Agronomy, Madison, WI, pp. 149-158.
Rieuwerts, J.S., Ashmore, M.R., Farago, M.E., 2006. The influence of soil characteristics on the extractability of $\mathrm{Cd}, \mathrm{Pb}$ and $\mathrm{Zn}$ in upland and moorland soils. Sci. Total Environ. 366, 864-875.

Sax, N.I., 1984. Dangerous Properties of Industrial materials. Van Nostrand Reinhold, New York, pp. 23-58.

Shan, X.Q., Wang, Z.W., Wang, W.S., Zhang, S.Z., Wen, B., 2003. Labile rhizosphere soil solution fraction for prediction of bioavailability of heavy metals and rare earth elements to plants. Anal. Bioanal. Chem. 375, 400-407.

Shuman, L.M., 1982. Separation soil iron and manganese oxide fractions for microelement analysis. Soil Sci. Soc. Am. J. 46, 1099-1102.

Shtangeeva, I., 2004. Trace and Ultratrace Elements in Plants and Soil. WIT Press, Southampton, UK, pp. 263-270.

Suzuki, K.T., Kobayashi, E., Ito, Y., Ozawa, E., 1992. Localization and health effects of lanthanum chloride instilled intratracheally into rats. Toxicology $76,141-152$

Tong, S.L., Zhu, W.Z., Gao, Z.H., Meng, Y.X., Peng, R.L., Lu, G.C., 2004. Distribution characteristics of rare earth elements in children's scalp hair from a rare earths mining area in southern China. J. Environ. Sci. Health. Part A, Environ. Sci. Toxic Hazard. Substance Control 39, 2517-2532.

Ure, A.M., Quevauviller, P., Muntau, H., Griepink, B., 1993. Speciation of heavy metals in soils and sediments. An account of the improvement and harmonization of extraction techniques undertaken under the auspices of the BCR of the commission of the European communities. Int. J. Environ. Anal. Chem. 51, 135-151.

Wang, Z.W., Shan, X.Q., Zhang, S.Z., 2001. Comparison of speciation and bioavailability of rare earth elements between wet rhizosphere soil and aireddried bulk soil. Anal. Chim. Acta 441, 147-156.

Wang, W.S., Shan, X.Q., Wen, B., Zhang, S.Z., 2003. Relationship between the extractable metals from soils and metals taken up by maize roots and shoot. Chemosphere 53, 523-530.

Wang, X.P., Shan, X.Q., Zhang, S.Z., Wen, B., 2004. A model for evaluation of the phytoavailability of trace elements to vegetables under the field conditions. Chemosphere 55, 811-822.

Whalley, C., Grant, A., 1994. Assessment of the phase selectivity of the European community Bureau of Reference (BCR) sequential extraction procedure for metals in sediment. Anal. Chim. Acta 291, 287-295.

Wear, J.I., Evans, C.E., 1968. Relationship of zinc uptake by corn and sorghum to soil zinc measured by three extractants. Soil Sci. Soc. Am. Proc. 32, $543-546$.

Wen, B., Yuan, D., Shan, X.Q., Li, F.L., Zhang, S.Z., 2001. The influence of rare earth element fertilizer application on the distribution and bioaccumulation of rare earth elements in plants under field conditions. Chem. Speciat Bioavailab. 13, 39-48.

Xu, X.K., Zhu, W.Z., Wang, Z.J., Witkamp, G.J., 2002. Distributions of rare earth and heavy metals in field-grown maize after application of rare earthcontaining fertilizer. Sci. Total Environ. 293, 97-105.

Zhang, J., Liu, C.Q., 2004. Major and rare earth elements in rainwaters from Japan and East China sea: natural and anthropogenic sources. Chem. Geo. 209, 319-326.

Zhang, S.Z., Shan, X.Q., 1997. The determination of rare earth elements in soil by inductively coupled plasma mass spectrometry. At. Spectr. 18, 140-144.

Zhang, S.Z., Shan, X.Q., 2001. Speciation of rare earth elements in soil and accumulation by wheat with rare earth fertilizer application. Environ. Pollut. $112,395-405$.

Zhang, S.Z., Shan, X.Q., Li, F.L., 2000. Low-molecular-weight organic acids as extractant to predict plant bioavailability of rare earth element. Int. J. Environ. Anal. Chem. 76, 283-294.

Zhang, F.S., Yamasaki, S., Kimura, K., 2001. Rare earth element content in various waste ashes and the potential risk to Japanese soil. Environ. Int. 27, 393-398. 